\title{
Monitorização da Satisfação dos Turistas com os Safaris
}

\author{
Monitoring Tourists'Satisfaction with Safaris
}

\section{Monitorización de la Satisfacción de los Turistas con los Safaris}

Cristina Cavalcanti Martins ${ }^{1}$

Julio Costa Mendes ${ }^{2}$

Maria Manuela Martins Guerreiro ${ }^{3}$

\section{Resumo}

Este estudo visa compreender o nível de satisfação com a experiência de participação em safaris no Algarve. Os turistas em busca de experiências inovadoras encontram no safari uma forma para estar em contacto com a natureza e com a cultura local. O Algarve possui áreas de protecção especial, com grande variedade de fauna e flora, enfim um rico ambiente ecológico, tornando o safari um atractivo para os turistas que estão em busca de aventura. A técnica utilizada para a recolha de dados foi através de questionário. A amostra é constituída de 303 participantes. Para análise dos dados, recorreu-se à análise factorial (ACP). Após o estudo, chegou-se à conclusão de que, no que respeita à satisfação, os atributos afectivos revelaram níveis elevados de satisfação, enquanto que os atributos cognitivos apenas revelaram níveis razoáveis de satisfação.

Palavras-chave: safaris; satisfação; experiência turística; afectivos; cognitivos.

\section{Abstract}

This study aims to understand the level of satisfaction with the experience of taking part in safaris in the Algarve region. Tourists looking for innovative experiences find in safaris a way to make contact with nature and local culture. The Algarve region has Special Protection Areas with a great variety of flora and fauna, a rich ecological environment, which turns safaris into an attraction to tourists in search of adventure. The approach used to collect data was through a questionnaire. The sample is made up of 303 participants. To analyse the data a factor analysis (ACP). After the study, one can conclude that, when it comes to satisfaction, the attributes concerning the realm of the affective reveal high levels of satisfaction, while the attributes related to the cognitive realm only show reasonable levels of satisfaction.

Keywords: safaris; satisfaction; touristic experience; affective; cognitive.

\footnotetext{
${ }^{1}$ Mestre em Marketing pela Universidade do Algarve (Portugal).Email: crisbc93@gmail.com.

2 Doutorado em Gestão, Professor Auxiliar na Faculdade de Economia da Universidade do Algarve. Email: juliocostamendes@hotmail.com.

${ }^{3}$ Doutoranda em Gestão, Especialidade em Marketing, Assistente na Faculdade de Economia da Universidade do Algarve. Email: mmguerre@ualg.pt.
} 


\section{Resumen}

Este estudio pretende comprender el nivel de satisfacción con la experiencia de participación en safaris en El Algarve. Los turistas en busca de experiencias innovadoras encuentran en el safari una forma para estar en contacto con la naturaleza y con la cultura local. El Algarve posee áreas de protección especial con gran variedad de fauna y flora, esencialmente un rico entorno ecológico, transformando el safari en un atractivo para los turistas que están en busca de aventura. La técnica utilizada para la recolección de datos fue a través de un cuestionario. La muestra está constituida por 303 participantes. Para el análisis de los datos se recurrió al análisis factorial (ACP). Después del estudio se llegó a la conclusión de que, en lo que respecta a la satisfacción, los atributos afectivos revelaron niveles elevados de satisfacción, mientras que los atributos cognitivos apenas revelaron niveles razonables de satisfacción.

Palabras-clave: safaris, satisfacción, experiencia turística, afectivos, cognitivos.

\section{Introdução}

O Turismo de Aventura tem crescido nos últimos anos, tendo-se tornado um nicho de mercado importante no sector turístico com um rápido crescimento no conjunto das actividades turísticas de ar livre (WILLIAMS e SOUTAR, 2009, pg 413). De facto, a pesquisa realizada a este nível, em Portugal, evidencia o interesse crescente dos turistas por actividades que envolvam a natureza. No contexto destas actividades, encontra-se o safari.

O Safari, tal como acontece com actividades turísticas que envolvam a natureza, foi classificado como Turismo de Aventura, uma vez que privilegia o contacto com a natureza e com as tradições, corresponde a um produto turístico oferecido em todo o Algarve (TURISMO DO ALGARVE, online, 2009).

A interpretação literal do conceito de safari remete-nos para a caça ou observação de animais selvagens, estando associados a África. No entanto, no âmbito da presente investigação, o safari deve ser interpretado como uma actividade de observação da fauna e paisagens, bem como de contacto com a flora da região, visando ainda conhecer os costumes locais (TURISMO DO ALGARVE, online, 2009).

A maioria dos participantes é turista estrangeiro, que vem ao Algarve durante as férias, atraídos, em geral, pelo "Sol e Mar". Contudo, verifica-se uma procura crescente de actividades mais diversificadas ao ar livre entre as quais aquelas que se enquadram no 
conceito de turismo de aventura. Neste sentido, compreender o nível de satisfação face à experiência turística são informações relevantes, na medida em que possibilita aos gestores o desenvolvimento de estratégias que proporcionem experiências turísticas satisfatórias. Mossberg (2007 pg 60) refere que, "para que um fornecedor de serviços turísticos seja bem sucedido, é fundamental compreender como as empresas podem fornecer as circunstâncias que aumentam a satisfação das experiências dos clientes".

A questão que se coloca é a de saber se estarão os safaris no Algarve a proporcionar experiências satisfatórias. Neste contexto, o objectivo geral deste estudo é compreender o nivel de satisfação com a experiência de participação em safaris no Algarve. Por sua vez, os objectivos específicos são os seguintes:

- Definir o perfil dos participantes em safaris;

- Determinar o nível de satisfação face à experiência turística.

Com intuito de compreender as experiências dos participantes no âmbito deste estudo, tornase necessário responder as seguintes questões de investigação:

- Qual o perfil dos participantes de safari?

- Qual o nível de satisfação dos turistas com a experiência turística?

- Quanto à perspectiva afectiva desta experiência, está sendo positiva ou negativa?

- Os participantes estão mais satisfeitos com os atributos afectivos ou cognitivos?

- Qual o nível de satisfação global com a experiência turística?

- Em que medida os participantes estão fidelizados?

$\mathrm{O}$ artigo estrutura-se em três partes onde estão desenvolvidas as etapas fundamentais para a realização do estudo. Na introdução é justificada a razão de ser deste estudo e apresentados os objectivos, o problema a investigar e a relevância do tema. Segue-se a primeira parte correspondente à revisão da literatura, onde se apresentam e discutem os temas relacionados com o estudo, classificando os conceitos, as abordagens e os modelos teóricos presentes na literatura. Na segunda parte, apresenta-se a metodologia que norteia o estudo empírico, onde se apresentam as técnicas de recolha de informação e de análise de dados. Os resultados da análise de dados e a sua discussão são apresentados na terceira parte. Aí desenvolve-se a 
análise dos resultados apurados através de inquérito por questionário. Segue-se a discussão dos resultados obtidos, onde se comparam os resultados com a informação recolhida na revisão bibliográfica. Por último, apresenta-se a conclusão geral do estudo.

\section{Revisão da Literatura}

\subsection{Experiência turística}

Os indivíduos estão à procura de sensações e estão dispostos a pagar por experiências agradáveis, e não apenas adquirir físicamente produtos ou serviços. Este novo contexto mostra uma evolução onde o que conta são as emoções, os sentimentos e o pensamento no momento em que estão envolvidos com a experiência. Schmitt (2000 pg 41) sugere que "as experiências são o resultado do encontro e da vivência de situações. As experiências geram, na realidade, valores sensoriais, emocionais, cognitivos e comportamentais".

De acordo com Boswijk, Thijssen e Peelen (2007 pg 06) "uma experiência é essencialmente uma forma de comportamento. É um processo em que o sentimento desempenha um papel importante. A lógica das emoções determina como um indivíduo lida com o ambiente e as pessoas.

Quanto ao conceito de experiência turística, Tussyadiah e Fesemair (2009 pg 24) referem que "a experiência turística é um termo socialmente construído através do qual o significado da experiência turística está associada a múltiplas interpretações do social, ambiental e dos componentes da actividade global da experiência". O turismo envolve um aspecto hedonista, ou seja, "um desejo de experimentar diferentes tipos de prazer corporal e espiritual, o que implica a negação do quotidiano" (TUSSYADIAH e FESENMAIR, 2009 pg 26).

Enquanto o hedonismo realista tende a procurar os prazeres corporais, tendo em conta as experiências passadas; o hedonismo imaginativo baseia-se em prazeres procurados através da estimulação emocional e espiritual, sendo a sua força motriz a imaginação gerada por novas experiências (TUSSYADIAH e FESENMAIR, 2009). As experiências turísticas representam aspectos da vida e influenciam os indivíduos através da troca de emoções e sentimentos (LARSEN e MOSSBERG, 2007). A experiência pode ser concebida como um fenómeno mental. É evidente que os fenómenos mentais incluem as expectativas, percepções e 
memórias e todos estes elementos fazem parte da experiência turística. Sendo assim, o turista procura activamente experiência turística, onde possa ter uma oportunidade de entretenimento (LARSEN e MOSSBERG, 2007).

\subsubsection{A Importância da criatividade para a experiência turística}

Uma forma de agregar valor, diversificar e dinamizar o desenvolvimento da experiência turística é através da participação activa do turista, bem como utilizar o seu próprio potencial criativo (RICHARDS e WILSON, 2006). O turismo criativo e a autenticidade das experiências turísticas são relevantes, na medida em que a autenticidade é realizada de forma genuína. Richards e Wilson (2007) defendem que há uma conotação negativa quando a autenticidade é encenada, uma vez que a mesma é vista como uma desvalorização à "autêntica" experiência.

Torna-se necessário que a experiência turística seja trabalhada, de forma a proporcionar enriquecimento cultural e visual. Ao adicionar história de vida e promover encontros com objectos reais, de forma autêntica, as experiências podem ser melhoradas. As lembranças, artesanato e fotos são exemplos de objectos através dos quais os turistas tendem a traduzir a sua experiência. Estes objectos fornecem evidências de terem "encontrado o autêntico" (HARVEY, 2004 pg 08).

Finalmente, o turismo criativo é interessante, na medida em que está associado ao dinamismo e orientado para o futuro. Portanto, a interacção com o turista é relevante, uma vez que é uma forma de lhe proporcionar experiência turística significativa (RICHARDS e WILSON, 2006).

\subsubsection{A aventura e a experiência turística}

No turismo, como na maioria dos serviços, a experiência de consumo é dificultada pela intangibilidade, dinamismo e subjectividade. Uma melhor compreensão das dimensões sóciopsicológicas do consumo de aventura irão ajudar as organizações a criarem estratégias de marketing direccionadas ao público-alvo de forma mais eficaz. Muitos dos novos destinos de turismo de aventura e os respectivos produtos turísticos evoluíram para atender às necessidades mais exigentes dos consumidores (Williams e Soutar, 2009). 
Existe uma falta de entendimento sobre a natureza das experiências dos turistas que estão em busca de aventura, em relação à qualidade do serviço, ao valor funcional e à sua satisfação. Williams e Soutar (2009 pg 415) as experiências de consumo de turismo incluem uma complexa mistura de componentes funcionais, objectivas e tangíveis, bem como subjectivas e hedonista, ou seja, o emocional e componentes tradicionais e simbólicas. Para que as experiências dos turistas sejam percepcionadas como coincidentes ou superiores às expectativas, é preciso que os gestores de organizações turísticas ofereçam um valor funcional que proporcione rapidez, habilidade e eficiência. Ou seja, que tenham capacidade administrativa e de gestão (WILLIAMS e SOUTAR, 2009).

O valor emocional refere-se a "uma dimensão sócio-psicológica que está dependente da capacidade de um produto para despertar sentimentos ou estados de afectividade". No turismo, as interacções entre os turistas e os guias turísticos, o reconhecimento individual ou o prestígio obtido podem proporcionar valor social. O valor epistémico acontece quando um produto desperta a curiosidade, prevê a novidade e satisfaz o desejo de conhecimento (WILLIAMS e SOUTAR, 2009 pg 416).

Ao criar e proporcionar aos clientes um valor, superior àquele que a concorrência oferece, torna-se necessário que as organizações definam a sua oferta, de forma a promover experiências agradáveis para os consumidores. Através das variáveis do marketing mix de serviços, isto é, pessoas (people), processos (process) e evidência física (physical evidence) as organizações podem concretizar grande parte do seu propósito (COOPER, FLETCHER, WANHILL, GILBERT, SHEPHERD, 2001 pg 447; KOTLER E KELLER, 2006).

Não é possível uma organização turística dar ou vender experiências turísticas a um turista. A organização pode criar as circunstâncias e o ambiente em que o turista pode ter uma experiência positiva. "O turista é um co-construtor deste ambiente de experiência. Durante o consumo os turistas interagem com o pessoal da organização, outros turistas, produtos, lembranças e o ambiente físico" (LARSEN e MOSSBERG, 2007 pg 05).

\subsection{Satisfação}

A satisfação para com a experiência de consumo tem sido um tema recorrente em vários estudos, uma vez que a satisfação apresenta uma relação positiva com a retenção e possibilita o passa-palavra positivo. Oliver (1993 pg 418) sublinha que "uma experiência de compra 
satisfatória pode ser uma razão para o interesse contínuo num produto ou serviço, que poderia levar à repetição de compra”. Neste contexto, tem crescido o interesse dos investigadores em compreender a satisfação do cliente.

Torna-se necessário, então, investigar o processo de satisfação, quer no sector do turismo em geral, quer em actividades específicas, como montanhismo, safaris e outros. Bosque e Martín (2008 pg 552) defendem que uma exploração de conceitos psicológicos, como atitudes, experiências e satisfação é necessário para a compreensão da psicologia do consumidor no turismo. Contudo, as dimensões cognitiva e afectiva têm sido reconhecidas na literatura como relevantes para explicar a satisfação do turista em relação a uma experiência de consumo.

De acordo com a abordagem cognitiva, a satisfação dos consumidores é uma avaliação, onde os indivíduos esperam que a experiência de consumo atenda ou exceda as suas expectativas (BOSQUE e MARTÍN, 2008). Devido ao envolvimento afectivo/emocional, a satisfação é também definida como um resposta emocional derivada de uma experiência de consumo (OKELLO e YERIAN, 2009 pg 606). Por outras palavras, os indivíduos são influenciados por emoções e sentimentos decorrente da experiência de consumo.

\subsubsection{Abordagem cognitiva, afectiva e comportamental}

Uma atitude é o modo como alguém pensa, sente e age em relação a algum aspecto de um ambiente, um produto, um serviço ou uma experiência de consumo. A atitude possui três componentes: a cognitiva (crenças), a afectiva (sentimentos) e comportamentais (tendências a reagir de determinado modo) (HAWKINS et al., 2007 pg 201). Nesta visão, a abordagem cognitiva é a soma do conjunto da informação do meio em que esse indivíduo vive e a informação que já se encontra registada na sua mente. "O cognitivo está relacionado com o mental, ou seja, representação de objectivos, conhecimentos ou crenças" (Bosque e Martín, 2008 pg 553).

De acordo com a abordagem cognitiva, a satisfação é uma resposta do consumidor para a congruência entre o desempenho e o padrão de comparação. Neste sentido, a desconfirmação é o principal determinante deste conceito, enquanto as expectativas são o padrão de comparação na avaliação do cliente (BOSQUE e MARTíN, 2008). A visão actual oferece uma experiência de integração para explicar a satisfação do consumidor, considerando-se 
cognitiva a desconfirmação e afectiva, as dimensões emocionais prévias (BIGNÉ, ANDREU e GNOTH, 2005).

Quanto à abordagem afectiva, os sentimentos ou reacções emocionais face a uma experiência de consumo, serviço ou produto representam a componente afectiva de uma atitude. Após a experiência turística, o domínio afectivo do indivíduo terá sido marcado de forma positiva ou negativa. Westbrook (1987 pg 260) sublinha que "a resposta emocional dos consumidores relevantes na pós-compra, pode ser descrita por bipolar, dimensões opostas de emoções positivas e negativas".

Quando a experiência turística é positiva são esperados sentimentos de alegria, prazer, entre outros. Por outro lado, quando a experiência é negativa esperam-se reacções de raiva, nojo e desprezo. Westbrook (1987 pg 260, 267) defende que "tanto dimensões de afecto positivo como negativo podem conter um aspecto de surpresa. As respostas emocionais agradáveis e desagradáveis no pós-compra estão relacionadas com a avaliação da satisfação, em partes aproximadamente iguais e na direcção oposta". Finalmente, a abordagem afectiva baseia-se no pressuposto de que os sentimentos são uma variável relevante para a experiência do consumidor (BIGNÉ ET AL., 2005; BOSQUE e MARTÍN, 2008).

A abordagem comportamental de uma atitude é a soma da tendência de um indivíduo responder de certa forma face a um objecto ou actividade. Uma série de decisões para comprar ou não um bilhete para um safari ou para recomendar este safari a amigos reflecte a componente de comportamento de uma atitude. Nesta perspectiva, "a componente comportamental proporciona tendências de reacção ou intenções comportamentais. Os comportamentos reais reflectem essas intenções, na medida em que são modificados pela situação em que o comportamento ocorre" (HAWKINS ET AL., 2007: 204).

\subsubsection{Factores que influenciam as expectativas dos clientes}

As expectativas dos clientes em relação a um produto/serviço ou experiência são criadas tendo em consideração vários factores tais como experiências anteriores, a publicidade, e o passa-palavra. Após o consumo, o consumidor comparará o produto/serviço ou experiência real com o esperado (GLENN, PARASURAMAN e GREWAL, 1998). As experiências anteriores do consumidor influenciam o desempenho da experiência de consumo, e servem de comparação entre o passado e o presente. Yoon e Uysal (2005 pg 47) sugerem que "os 
consumidores comparam outras alternativas de lazer ou o mesmo tipo de lazer realizado em outras localidades no passado. A diferença entre as experiências passadas e a presente pode ser uma norma usada para avaliar a satisfação".

É através da publicidade que as organizações procuram informar, persuadir, e lembrar os consumidores, de forma directa ou indirecta, sobre serviços, experiências ou produtos que comercializam, provocando, assim, o desejo de comprar e levá-lo a acção (KOTLER e KELLER, 2006 pg 532).

Estudos mostram que os clientes são mais propensos a recorrer à comunicação passa-palavra, em virtude da intangibilidade e natureza da experiência turística. Matos e Rossi (2008) sublinham que o nível de satisfação do cliente tem uma influência sobre dois comportamentos de compra, ou seja, as intenções de recompra e o passa-palavra.

Existem vários estudos que analisam o efeito significativo da satisfação sobre a actividade do passa-palavra. Matos e Rossi (2008 pg 580) afirmam que "há um efeito positivo significativo das experiências satisfatórias sobre a actividade do passa-palavra" De acordo com Thomas e Sasser (1995) sublinham que a satisfação deve ser avaliada com base na escala de Likert. No nível mais baixo de satisfação, ou seja, nível um os participantes, em geral, abandonam a organização e estão propensos a recomendar negativamente a familiares e amigos. Nos níveis dois a quatro, os participantes estão, apenas, satisfeitos e podem mudar de fornecedor quando surge uma oferta melhor. No nível cinco, o participante tem grande probabilidade de repetir a compra e recomendar positivamente a experiência.

Como a vida é feita de experiências, é relevante que a empresa proporcione experiências agradáveis, uma vez que a satisfação está directamente relacionada com o resultado destas experiências (BEEHO e PRENTICE, 1997; BOSWIJK ET AL., 2007; GILMORE, 2003).

\section{Estudo Empírico}

\subsection{Análise do contexto envolvente}

Os safaris cujos participantes foram objecto deste estudo são realizados no Algarve, o principal destino turístico português. A população definida para o estudo em causa é constituída pelos participantes de safaris no Algarve durante o período da realização dos 
inquéritos. Para o efeito foram contactadas nove empresas classificadas pelo Turismo do Algarve como responsáveis pela organização dos safaris na região, três das quais aceitaram participar deste estudo, a Tui Portugal - Agência de Viagens e Turismo S.A., a Portitours Agência de Viagens e Turismo Lda., e a Riosul - Viagens e Turismo Lda.

As empresas ficaram encarregadas de promoverem o preenchimento dos inquéritos junto aos participantes. Assim sendo, foram distribuídos 628 questionários entre os dias 8 de Julho e 8 de Agosto de 2009. Dos 628 questionários distribuídos, foram recolhidos 392, observando-se que 37 apresentavam inconsistências e 52 estavam incompletos, resultando assim um total de 303 inquéritos em condições de serem analisados.

\subsection{Instrumento de recolha de dados}

Foi elaborado um questionário centrado na satisfação com a experiência turística. No início do questionário dão-se indicações sobre o objectivo do estudo e a forma como este deve ser preenchido.

A primeira questão teve como objectivo medir o nível de satisfação com a experiência, em relação aos atributos cognitivos. Como instrumento de resposta foi utilizada a escala de Likert 5 pontos (1 muito insatisfeito a 5 muito satisfeito).

O modelo utilizado para elaborar os itens de satisfação foi Tourist Satisfaction a CognitiveAffective Model desenvolvido por Bosque e Martín (2008). Esse modelo mede os atributos cognitivos e afectivos da experiência turística. Foi desenvolvido com base na escala de Atributos para Medir a Imagem de Destino, proposta por Echtner e Ritchie (2003). De acordo com Bosque e Martín (2008: 552), "esse modelo é relevante para a organização, na medida em que permite investigar o processo de satisfação e contribuir para uma melhor compreensão da psicologia do consumidor".

Foram utilizados 13 itens para a realização do modelo de atributos cognitivos, como é possível verificar no Quadro 1: 
Quadro 1 - Modelo para Medir a Componente Cognitiva da Satisfação

\begin{tabular}{|c|c|}
\hline \multicolumn{2}{|c|}{ ATRIBUTOS COGNITIVOS } \\
\hline 1. Beleza das paisagens & 8. Oportunidades para aventura \\
\hline 2. Variedade da flora & 9. Relaxante \\
\hline 3. Variedade da fauna & 10. Gastronomia rica e variada \\
\hline 4. Cenário natural e atractivo & 11. Segurança \\
\hline 5. Aprender sobre os costumes locais & 12. Pessoal hospitaleiro \\
\hline 6. Actividades culturais interessantes & 13. Acessibilidades boas \\
\hline 7. Oportunidade para aumentar o conhecimento & \\
\hline
\end{tabular}

Fonte: Adaptado de Bosque e Martín (2008) e Echtner e Ritchie (2003)

A segunda questão pretendeu-se medir a satisfação global com esta experiência. Tal como referido na primeira questão, foi utilizado a escala de Likert.

No que respeita à terceira questão sobre a perspectiva afectiva da satisfação, pretendeu-se compreender qual o nível de satisfação dos participantes, em relação as emoções e sentimentos com esta experiência turística. Foi utilizado uma escala de diferencial semântico, composta por pares de adjectivos opostos (agradável - desagradável e excitante - sombrio) com base no estudo de Bosque e Martín (2008).

As questões que envolvem a fidelização, visaram identificar até que ponto o participante ficou fidelizado e em que medida está disposto a repetir e recomendar positivamente esta experiência turística. Por fim, as questões relacionadas com a caracterização sóciodemográfica, formuladas com o fim de identificar o perfil dos respondentes.

Antes de iniciar os inquéritos, foi realizado um pré-teste junto de 30 participantes em safaris no Algarve, com o objectivo de verificar a adequação do questionário. Este pré-teste revelou que o instrumento desenvolvido para este estudo se adequava ao perfil do respondente não tendo sido introduzidas alterações relevantes.

\subsection{Análise de Dados}

Após a recolha dos dados, estes foram analisados, recorrendo-se ao programa estatístico SPSS 15. Relativamente aos procedimentos utilizados no tratamento dos dados, algumas variáveis ordinais do presente estudo foram descritas com medidas próprias de variáveis quantitativas (média e desvio padrão). 
No presente estudo, recorreu-se a alguns testes, com os seguintes objectivos: comparar a tendência central de uma variável entre grupos independentes, averiguar em que pares de grupos se encontram diferenças significativas, verificar a correlação existente entre uma variável qualitativa (ordinal) e outra quantitativa e averiguar se as variáveis se encontravam suficientemente correlacionadas entre si para entrarem numa análise factorial.

À semelhança do que acontece numa grande parte dos estudos realizados no âmbito das ciências sociais, também no presente estudo se optou pela Análise de Componentes Principais (ACP). O nível de significância alfa utilizado foi de $5 \%$.

\section{Análise e Discussão de Dados}

\subsection{Caracterização sóciodemográfica}

Ao analisar a caracterização sócio-demográfica dos respondentes, observa-se que em termos de proveniência, a Inglaterra $(31,7 \%)$ e Países Baixos $(32,3 \%)$ são os mais representados. Contudo, há uma quantidade significativa provenientes de outras nacionalidades $(30,4 \%)$. As idades variam entre 10 e 70 anos, sendo a idade média 35, 73 anos $(\mathrm{DP}=14,28)$. Em relação ao género, a amostra do presente estudo se encontra dividida de forma equilibrada, isto é, masculino $(48,18 \%)$ e o feminino $(51,82 \%)$. Relativamente ao estado civil, verifica-se que a maioria é casado ou vive numa união estável $(56,4 \%)$ e que $(41,9 \%)$ são solteiros. Apenas $(0,7 \%)$ são viúvos e $(1,0 \%)$ a mencionarem ter outro tipo de estado civil. Ao analisar o grau de escolaridade, observa-se que a maioria tem formação universitária $(54,5 \%)$, tendo os restantes formação secundária $(32,3 \%)$ e básica $(13,2 \%)$. No que diz respeito à ocupação, verifica-se que grande parte presta trabalho para outrem $(37,6 \%)$, havendo ainda $(21,5 \%)$ de estudantes, $(13,9 \%)$ de profissionais liberais, $(9,6 \%)$ de administradores, $(5,3 \%)$ domésticas, $(4,5 \%)$ reformados e $(6,6 \%)$ outras.

\subsection{Satisfação com a experiência turística}

Após a realização do safari, os respondentes no âmbito deste estudo sentiram satisfação, sobretudo dada a beleza das paisagens $(M=4,46 ; D P=0,71)$, a hospitalidade do pessoal $(M=$ $4,39 ; D P=0,74)$ e a oportunidade para aumentarem os seus conhecimentos $(M=4,30 ; D P=$ $0,64)$. Por outro lado, os níveis de satisfação mais baixos deveram-se à variedade da fauna $(M$ 
$=3,68 ; D P=1,01)$, na variedade e riqueza da gastronomia $(M=3,73 ; D P=0,87)$ e às dimensões relaxante do safari $(M=3,92 ; D P=0,87)$.

Com o objectivo de se reduzir a dimensionalidade dos 13 itens que compõem o modelo de satisfação com a experiência, procedeu-se a uma análise factorial (método ACP). A rejeição da hipótese de que os dados representam uma matriz diagonal através do teste de Bartlett ( $p$ $<.001)$ e o valor KMO de ,87 permite-nos concluir que os dados estão suficientemente correlacionados de modo a justificarem este tipo de análise.

Continuando a usar-se o critério de Kaiser, os dados sugerem a extracção de três factores, com os seguintes valores próprios e respectivas variâncias explicadas (após rotação Varimax): 2,98 $(22,92 \%) ; 2,81(21,58 \%)$ e $2,32(17,87 \%)$. Desta forma, no seu todo os três factores conseguem explicar 62,37\% da variabilidade dos 13 itens originais. Sendo assim, os 13 itens foram distribuídos em três factores: Natureza, Serviços e infraestrutura e Cultura. (Tabela $3.1)$.

Tabela 1 - Factores e Respectivos Itens de Satisfação com a Experiência Turística

\begin{tabular}{|l|l|}
\hline \multicolumn{1}{|c|}{ Factores } & \multicolumn{1}{c|}{ Itens de Satisfação } \\
\hline & Beleza das paisagens \\
Natureza & Variedade da flora \\
& Variedade da fauna \\
& Cenário natural e atractivo \\
& Oportunidades para aventura \\
\hline Serviços e & Relaxante \\
Infraestrutura & Gastronomia rica e variada \\
& Segurança \\
& Pessoal hospitaleiro \\
& Acessibilidades boas \\
\hline \multirow{2}{*}{ Cultura } & Aprender sobre os costumes locais \\
& Actividades culturais interessantes \\
& Oportunidade para aumentar o conhecimento \\
\hline
\end{tabular}

Fonte: Elaboração própria

$\mathrm{Na}$ sequência dos resultados obtidos através da análise factorial, procedeu-se também neste caso à análise da consistência interna dos factores extraídos. Os alfas de Cronbach obtidos são respectivamente de 0,83 no factor Natureza; 0,80 no factor Serviços e Infraestrutura e de 0,80 no factor Cultura; a Satisfação Total (13 itens) teve por sua vez uma alfa de, 89. Também 
aqui, qualquer destes valores remete para uma fiabilidade interna adequada e, em todas as escalas a remoção de qualquer item deixa o coeficiente alfa praticamente inalterado.

Quanto às medidas descritivas da satisfação com a experiência turística, verifica-se que as médias observadas nas diferentes escalas apresentam todas valores acima dos pontos intermédios teóricos, 15 na Natureza $(M=20,81 ; D P=3,11)$ e Serviços e Infraestrutura $(M=$ 20,33; $D P=2,99)$, na medida em que a pontuação mínima é de 5 e a máxima é 25; 9 na Cultura $(M=12,61 ; D P=1,81)$, pois a pontuação mínima possível é de 3 e a máxima de 15 . Também a Satisfação Total $(M=53,74 ; D P=6,68)$ apresenta uma média bastante acima de 39, que corresponde ao ponto intermédio da escala. Assim, os dados sugerem níveis de satisfação com esta experiência turística bastante razoáveis.

Os factores Natureza e Cultura incluem os itens que causaram mais satisfação. Pensa-se que estes factores tiveram maiores níveis de satisfação, devido a Região do Algarve possuir belas paisagens, onde é possível apreciar uma arquitectura com influência árabe espalhada por toda a região, bem como paisagens naturais com alguns tipos de flora existente apenas no Algarve.

Os respondentes são, em geral, turistas europeus, muitos vêm de grandes cidades, sentem necessidade de contacto com a natureza e, por isso, acham interessante as paisagens naturais. No primeiro factor, apenas "a variedade da fauna" provocou baixos níveis de satisfação. O que explica este resultado, às vezes, é em virtude da palavra safari estar associada a animais da selva africana e ao fazer o safari no Algarve encontram, apenas, animais silvestres. Sendo assim, torna-se necessário conscientizar o target, através da comunicação, o tipo de fauna existente nessa região.

No segundo factor, o item "actividades culturais interessante" está entre os cinco itens com nível de satisfação mais baixo. Entretanto os itens "oportunidade para aumentar os conhecimentos" e "aprender sobre os costumes locais", são o terceiro e quinto, respectivamente, com maior nível de satisfação. Acredita-se que, quanto aos dois últimos itens, tiveram este resultado devido a diversidade cultural existente nesta região, onde é possível conhecer aldeias pitorescas, fortalezas que resistem ao longo dos séculos e belíssimas peças de artesanato feitas pelos habitantes da região. Em suma, é uma oportunidade para conhecer os costumes locais e adquirir mais conhecimento. 
No factor Serviços e Infraestrutura, os respondentes revelaram maiores níveis de satisfação quanto ao item "pessoal hospitaleiro", isto é, todas as pessoas envolvidas durante a experiência com o safari, principalmente os guias turísticos, desempenharam suas actividades de forma satisfatória. Entretanto, tiveram baixos níveis de satisfação com a "gastronomia rica e variada" e com as dimensões "relaxante" do safari. Acredita-se que o baixo nível de satisfação seja em virtude de algumas das empresas que praticam esta actividade não oferecem opções de menu (por exemplo, algumas empresas oferecem apenas frango, salada, batatas, arroz, vinho, água e frutas como sobremesa). Quanto às dimensões relaxante do safari, os indivíduos quando procuram uma actividade turística como esta, estão a procura de excitação, mas no final da experiência sentem necessidade de relaxar. Devido a mobilidade existente nesta actividade turística, bem como as características temporais é provável que os participantes não consigam relaxar.

\subsection{Perspectiva afectiva da satisfação}

Quanto à agradabilidade da experiência, quando se inquirem os participantes acerca da agradabilidade do safari, a grande maioria descreve esta experiência como muito agradável $(81,2 \%)$ ou como agradável (14,9\%). Apenas dois respondentes consideram a experiência desagradável $(0,7 \%)$.

Ao comparar-se a agradabilidade por nacionalidade (inglesa, holandesa, ou outra nacionalidade) foi possível encontrarem-se diferenças estatisticamente significativas $(H=$ 9,52; $g l=2 ; p=, 009)$. Mais concretamente, concluiu-se que os respondentes de outras nacionalidades (Média das Ordens $=160,03$ ) têm uma melhor percepção de agradabilidade face os holandeses (Média das ordens $=158,21$ ) e aos ingleses (Média das Ordens $=136,55$ ), (POST-HOC MANN-WHITNEY com ajustamento Bonferroni: $p=, 006$ e $p=, 004$ ).

Por outro lado, a comparação da agradabilidade segundo o género dos respondentes $(U=$ 10962,$\left.0 ; N_{l}=146 ; N_{2}=157 ; p=, 335\right)$, nível de instrução $(H=4,91 ; g l=2 ; p=, 086)$ e o escalão etário $(H=0,30 ; g l=2 ; p=, 862)$ não resultou em qualquer diferença significativa do ponto de vista estatístico.

No que respeita à excitação da experiência com o safari, quando se inquirem os participantes acerca do grau de excitação que a experiência lhes proporcionou, a maioria relata tê-la 
considerado muito excitante $(62,0 \%)$ e $(31,7 \%)$ excitante. Apenas $(0,7 \%)$ dos respondentes descreveram esta experiência como sombria.

Ao comparar-se o grau de excitação resultante da participação no safari, por nacionalidade (inglesa, holandesa, ou de outra nacionalidade), foi possível encontrarem-se diferenças estatisticamente significativas $(H=11,23 ; g l=2 ; p=, 004)$. Mais concretamente, concluiu-se que os ingleses consideraram esta experiência mais excitante (Média das ordens $=172,23$ ) que os holandeses (Média das Ordens $=137,27$ ) e que os respondentes de outras nacionalidades (Média das Ordens $=147,43)$, (POST-HOC MANN-WHITNEY com ajustamento BONFERRONI: $p=, 001$ e $p=, 015)$.

Também se pôde concluir que a percepção de excitação dos respondentes do sexo feminino (Média das Ordens $=160,62)$ se revelou significativamente superior $\left(U=10108,0 ; N_{l}=157\right.$; $N_{l}=146 ; p=, 038$ ) à dos respondentes do sexo masculino (Média das Ordens $=142,73$ ). Por outro lado, a comparação da percepção de excitação segundo o nível de instrução $(H=1,42$; $g l=2 ; p=, 493)$ e escalão etário $(H=0,93 ; g l=2 ; p=, 630)$ dos respondentes não resultou em qualquer diferença significativa.

Os respondentes revelaram elevados níveis de satisfação quanto a agradabilidade e excitação. Por outras palavras, a perspectiva afectiva foi positiva. Westbrook (1987) defende que uma resposta afectiva positiva contribui para explicação e previsão de comportamento pós-compra, bem como da satisfação.

A questão que se coloca é a de saber se os participantes estão mais satisfeitos com os atributos afectivos ou cognitivos. Ao comparar-se o grau de satisfação com a experiência turística resultante dos atributos afectivos (níveis elevados de satisfação) face a satisfação com a experiência turística resultante dos atributos cognitivos (níveis razoáveis de satisfação), têm um maior peso.

É importante compreender o envolvimento emocional e cognitivo em relação à experiência turística, uma vez que o grau de satisfação tanto do aspecto afectivo como cognitivo está ligado ao sucesso da empresa (BIGNÉ ET AL., 2005).

\subsection{Satisfação global com a experiência turística}


Quando inquiridos os participantes de safari acerca da sua satisfação global, a maioria refere encontrar-se muito satisfeita $(52,5 \%)$, havendo ainda $(43,6 \%)$ a mencionarem terem ficado satisfeitos. Apenas $(0,7 \%)$ dos respondentes relataram estarem muito insatisfeitos.

Quanto à satisfação global com esta experiência turística, observa-se que este resultado devese ao facto da satisfação global incluir os aspectos cognitivos (níveis razoáveis) e afectivos (níveis elevados) da satisfação com a experiência turística. Os sentimentos, ou seja, de prazer, excitação sentidas durante a experiência turística são variáveis críticas no que respeita à satisfação e fidelização. O estudo de Bigné et al. (2005) refere que as emoções sentidas durante a experiência turística são uma componente de satisfação e fidelização.

\subsection{Fidelização}

Ao inquirir os participantes acerca das intenções de repetirem a experiência, grande parte $(45,2 \%)$ revela ter duvidas em repetir a experiência. No entanto, (44,9\%) tencionam efectivamente repetir e $(9,9 \%)$ afirmam que não tencionam repetir.

Foi possível concluir que não existe qualquer associação significativa entre a intenção de repetir a experiência e a nacionalidade $\left(\chi^{2}=1,53 ; g l=4 ; p=, 822\right)$, o escalão etário $\left(\chi^{2}=7,40\right.$; $g l=4 ; p=, 116)$, o género $\left(\chi^{2}=1,136 g l=4 ; p=, 507\right)$ e o nível de instrução $\left(\chi^{2}=4,67 ; g l=\right.$ $4 ; p=, 322)$ dos respondentes.

Quando inquiridos os participantes acerca da recomendação do safari a familiares e/ou amigos, a esmagadora maioria dos respondentes recomendaria $(87,1 \%)$, havendo unicamente $(1,0 \%)$ dos respondentes que não o farão e $(11,9 \%)$ que talvez o recomendem.

Foi ainda possível concluir que existe uma pequena tendência para os ingleses estarem mais dispostos a recomendar $(94,8 \%)$ do que os holandeses $(86,7 \%)$ e os de outras nacionalidades $(80,7 \%)\left(\chi^{2}=12,22 ; g l=4 ; p=, 016 ; V\right.$ de Cramer $\left.=, 14\right)$. Por outro lado, não foram encontrados quaisquer associações entre a recomendação da experiência e o escalão etário $\left(\chi^{2}\right.$ $=3,44 ; g l=4 ; p=, 487)$, o género $\left(\chi^{2}=1,12 ; g l=4 ; p=, 571\right)$ e o nível de instrução $\left(\chi^{2}=\right.$ $2,00 ; g l=4 ; p=, 735)$.

No que se refere à fidelização, o estudo revelou que a esmagadora maioria dos participantes tem intenção de recomendar a familiares e amigos esta experiência turística. No entanto, grande parte afirmou que talvez a repita e $9,9 \%$ dos respondentes não têm intenção de repetir. 
Em suma, os níveis de satisfação em relação a experiência turística no âmbito dos aspectos afectivos e cognitivos não foram iguais. Por outras palavras, tiveram níveis razoáveis quanto aos aspectos cognitivos e elevados quanto aos aspectos afectivos. Acredita-se que este resultado interferiu em parte na fidelização. O resultado deste estudo, quanto ao passapalavra, é compatível com o estudo de Matos e Rossi (2008), uma vez que, afirma que as experiências satisfatórias possibilitam o passa-palavra positivo.

Quanto à intenção de repetir a experiência, grande parte revelou que talvez volte a repeti-la. Este resultado está em sintonia com o estudo de Thomas e Sasser (1995), que refere que a intenção de repetir a experiência depende do nível de satisfação, ou seja, entre os níveis dois a quatro os participantes estão satisfeitos e podem recomendar positivamente. Entretanto, se estiverem no nível cinco, os participantes têm grande probabilidade de repetirem a experiência.

Este estudo revelou que os atributos afectivos tiveram um maior peso na satisfação dos respondentes face os cognitivos. De acordo com este resultado, conclui-se que o nível de satisfação não chegou ao nível cinco, em virtude dos atributos cognitivos terem, como resultado, níveis razoáveis de satisfação.

\section{Conclusão Geral}

O safari no Algarve, como se apresenta actualmente, possibilita aos participantes conhecer, com mais pormenor, as tradições e costumes da região algarvia ao percorrer trilhos e caminhos pouco utilizados e conhecidos, usando para tal veículos todo-o-terreno, onde é possível apreciar diversos tipos de flora e fauna, usufruindo de bonitas paisagens (TURISMO DO ALGARVE, online, 2009).

Para responder ao objectivo do estudo, definiu-se numa estratégia assente na realização de inquéritos in situ. Neste sentido, foi realizado um estudo sobre a satisfação com a experiência turística. A importância de estudar a satisfação, de acordo com a revisão da literatura, reside no facto de está directamente relacionado com o sucesso da organização, favorecendo não apenas a empresa, mas todos os stakeholders. Portanto, este estudo explorou os processos cognitivos e afectivos da satisfação com a experiência turística no âmbito do safari. 
Neste contexto, Quanto ao perfil dos participantes de safaris, conclui-se que são provenientes da Holanda e Inglaterra. A maioria presta trabalho por conta de outrem e tem nível de escolaridade superior. Possuem, em média, 35 anos, grande parte é casado e procuram fazer esta experiência com a família.

No que respeita à satisfação no âmbito dos aspectos cognitivos, sentiram satisfação com a beleza das paisagens, a hospitalidade do pessoal e a oportunidade para aumentar os conhecimentos. No entanto, sentiram baixos níveis de satisfação quanto à variedade da fauna, gastronomia e com as dimensões relaxante do safari. Contudo, tiveram níveis de satisfação com esta experiência bastante razoáveis.

Quanto à perspectiva afectiva desta experiência, tanto com a agradabilidade do safari como com a excitação, foi positiva.

Ao comparar os atributos afectivos face os cognitivos da satisfação com a experiência turística, os participantes revelaram estar mais satisfeitos com os atributos afectivos.

Entretanto, no que respeita à satisfação global com a experiência, os participantes revelaram estar muito satisfeitos.

No que respeita à fidelidade, a esmagadora maioria está disposta a recomendar positivamente a experiência no âmbito do safari a familiares e amigos. Contudo, observou-se que quanto à repetir esta experiência, grande parte revela ter dúvidas.

É relevante que sejam desenvolvidos laços emocionais com o participante para incentivar a repetição de compra. Vários estudos indicam que há uma relação entre este tipo de comportamento e a repetição da experiência.

Com base nestes resultados, os gestores devem rever as actividades exercidas no safari, de forma a implementarem medidas para que os participantes se sintam relaxados, bem como melhorar a variedade da gastronomia. Quanto à variedade da fauna, salienta-se a necessidade de se implementar actividades que envolvam a fauna de forma criativa.

Os gestores precisam tornar a actividade do safari mais criativa e diversificada, para incentivar os participantes a repetir a experiência e aumentar os níveis de satisfação, no que respeita os atributos cognitivos. A estratégia de Marketing mix é um meio de tornar o 
ambiente mais atractivo. É imperioso trabalhar o ambiente físico, de forma a proporcionar um cenário onde os clientes possam ter uma experiência turística de alto nível.

Uma das limitações do estudo, o facto de ter sido realizado apenas em três empresas no Algarve, o que impede a generalização dos resultados encontrados para situações semelhantes em outras regiões do país ou do estrangeiro.

O motivo que explica o número de inquéritos não preenchidos deve-se à natureza da própria actividade, a qual não incentiva ao preenchimento por não dispor de características temporais e físicas que facilitem o preenchimento, dado implicar o ar livre e grande mobilidade. Nesta conformidade, a amostra não é representativa da população. Como sugestões de pesquisas futuras, sugere-se que seja feito um estudo sobre os safaris a nível nacional.

A principal mais valia deste estudo é o seu contributo para estas empresas conhecerem melhor o modo como os turistas se relacionam com actividades complementares em destinos turísticos maduros e excessivamente concentrados no produto "Sol e Mar". Com base neste estudo, é possível definir estratégias de marketing as quais correspondam com os resultados oriundos da satisfação com a experiência turística.

\section{Referências}

BEEHO, A. J. and PRENTICE R. C. Prentice. Conceptualizing the experiences of heritage tourists, Journal Management, 18, 2, 1997, pp. 75-87.

BIGNÉ, J. Enrique, ANDREU Luisa. and GNOTH Juergen. The Theme Park Experience: An Analysis of Pleasure, Arousal and Satisfaction, Tourism Management, 26, 2005, 833-844.

BOSQUE, I. R. And MARTÍN H. S. Tourist Satisfaction a Cognitive-Affective Model, Annals of Tourism Research, 35, 2, 2008, 551-573.

BOSWIJK, Albert, THIJSSEN Thomas; PEELEN E. A New Perspective on the Experience Economy. The European Centre for the Experience Economy, the Netherlands. 2007. [online], [citado em 01 de Abril de 2007]. Disponível em: <http://www.experience-economy.com/wcontent/UserFiles /File/Article\%20Lapland5.pdf $>$.

COOPER, Chris, FLETCHER J., WANHILL S., GILBERT D. and SHEPHERD R. Turismo, Princípios e Prática, 2a Edição, Porto Alegre, Bookman, 2001.

ECHTNER, C. M. And RITCHIE J. R. B. The Meaning and Measurement of Destination Image, The Journal of Tourism Studies, 14, 1, 2003, 37-48.

GILMORE, James. Frontiers of the Experience Economy. [online] USA, Batten Briefings, [citado em 01 de Agosto de 2003]. Disponível em: <http://www.darden.virginia.edu/ batten/pdf/bf_gilmore.pdf.>. 
GLENN, B. Voss, PARASURAMAN A. and GREWAL Dhruv. The Role of Price, performance, and expectations in determining satisfaction in service exchanges, Journal of Marketing, 62, October 4661, 1998.

HARVEY, William Robert. Authenticity and Experience Quality Among Visitors at a Historic Village [online], [citado em 06 de Fevereiro de 2004]. Disponível em: <http://scholar.lib.vt.edu/ theses/available/etd-03052004-132332/unrestricted/result.pdf>.

HAWKINS, Del I., MOTHERSBAUGH D. L. and BEST, R. J. Consumer Behavior: Building Marketing Stategy, 10 $0^{\mathrm{a}}$ Edition, New York, McGraw-Hill/Irwin, 2007.

KOTLER, Philip, KELLER K. L. Marketing Management, 12th Edition, New Jersey, Pearson Prentice Hall, 2006.

KOZAK, Metin. Comparative Analysis of Tourist Motivations by Nationality and Destinations, Tourism Management, 23, 2002, 221-232.

LARSEN, Svein, MOSSBERG Lena. The Diversity of Tourist Experiences, Scandinavian Journal of Hospitality and Tourism, 7, 1, 2007, 1-6.

MATOS, A. C. and ROSSI C. A. V. Word-of-mouth communications in marketing: a meta-analytic review of the antecedents and moderators, Journal of the Academy of Marketing Science, 36, 2008, 578-596.

MOSSBERG, Lena. A Marketing Approach to the Tourist Experience, Scandinavian Journal of Hospitality and Tourism, 7, 1, 2007, 59-74.

OKELLO, M. M., YERIAN S. Tourist satisfaction in relation to attractions and implications for conservation in the protected areas of the Northern Circuit, Tanzania, Journal of Sustainable Tourism, $17,5,2009,605-625$.

OLIVER, Richard. Cognitive, Affective, and Attribute Bases of the Satisfaction Response, Journal of Consumer Research, 20, 1993, 418-430.

RICHARDS, Greg and WILSON J. Tourism, Creativity and Development, London, Routledge, 2007.

RICHARDS, Greg and WILSON Julie. Developing Creativity in Tourist Experiences: A solution to the serial reproduction of culture? Tourism Management, 27, 2006, 1209-1223.

SCHMITT, Bernd H. Marketing Experimental, São Paulo, Nobel, 2000.

SOIFER, Jack. Empreender Turismo de Natureza, Lisboa, Offset Mais, S.A, 2008.

THOMAS, O. Jones and SASSER Jr, W. E. "Why satisfied customers defect", Harvard Business Review, Novembro/Dezembro, 1995, 88-99. [online] [último acesso em 08 Dezembro de 2009], Disponível em: $\quad<$ http://faculty.bschool.washington.edu/ryalch/NSTU/Why\%20Satisfied\%20 Customers\%20Defect.pdf $>$.

TURISMO DO ALGARVE [online], [último acesso 15 de Novembro de 2009]. Disponível em: < http://www.visitalgarve.pt $>$.

TUSSYADIAH, L. P. And FESENMAIR D. R. Mediating Tourist Experiences Access to Places Via Shared Videos, Annals of Journal Research, 36, 1, 2009, 24-40.

WESTBROOK, R. A. Product/Consumption Based Affective Responses and Postpurchase Processes, Journal of Marketing Research, 24, 8, 1987, 258-270.

WILLIAMS, David. Delivering a Distinct Customer Experience. [online] QCI. 2004 [último acesso: 09 Maio 2009]. Disponível em: < http://www.qci.co.uk/public face/Content/Delivering\%20a\%20 Distinct\%20Customer\%20Experience.pdf $>$. 
WILLIAM, Paul and SOUTAR Geoffrey N. Value, Satisfaction and Behavioral Intentions in an Adventure Tourism Context, Annals of Tourism Research, 36, 3, 2009, 413-438.

YOON, Yooshik and UYSAL Muzaffer. An Examination of the Effects of Motivation and Satisfaction on Destination Loyalty: A Structural Model, Tourism Management, 26, 2005, 45-56.

Recebido em: 15/02/2011

Aprovado em: 04//04/2011 